\title{
Excess molar volumes and viscosities of binary mixtures of 1,2-dimethoxyethane with chloroalkanes at 298.15 K
}

\author{
AMALENDU PAL*, GURCHARAN DASS and SANJAY SHARMA \\ Department of Chemistry, Kurukshetra University, Kurukshetra 136119 , \\ India \\ e-mail: kuru@doe.ernet.in
}

MS received 1 February 1999; revised 24 March 1999

\begin{abstract}
Excess molar volumes $\left(V_{m}{ }^{E}\right)$, viscosity deviations $(\Delta \ln \eta)$ and excess energies of activation for viscous flow $\left(\Delta G^{*}\right)$ are reported for non-electrolyte mixtures of 1,2-dimethoxyethane (monoglyme) and dichloromethane, trichloromethane, and tetrachloromethane at $298.15 \mathrm{~K}$ and at atmospheric pressure over the whole mole fraction range. The Prigogine-Flory-Patterson (PFP) model has been used to calculate $V_{m}{ }^{E}$, and the results are compared with experimental data. The Bloomfield and Dewan model has been used to calculate viscosity coefficients, which are compared with experimental data for three mixtures. These results have been analysed in terms of dipole-dipole interactions between 1,2-dimethoxyethane and chloroalkanes. The magnitude of the strength of interaction decreases with the dipole character of the molecule.
\end{abstract}

Keywords. Viscosity deviation; binary mixtures; 1,2-dimethoxyethane; chloroalkanes.

\section{Introduction}

Properties of liquid-liquid mixtures are technically very important as part of our studies on binary mixtures containing oxygen $\left(-\mathrm{O}_{-}\right)$and hydroxyl $\left(-\mathrm{OH}_{-}\right)$functional groups ${ }^{1-4}$. We report here the excess molar volume $\left(V_{m}{ }^{E}\right)$, viscosity deviation $(\Delta \ln \eta)$ and excess energies of activation for viscous flow $\left(\Delta G^{* E}\right)$ for mixtures containing 1,2dimethoxyethane (DME) with dichloromethane (DCM), trichloromethane (TCM), and tetrachloromethane (TC) at $298.15 \mathrm{~K}$ and at atmospheric pressure, with the aim of characterizing their possible interactions. Excess properties of binary mixtures containing chloroalkanes have previously been studied by several authors ${ }^{5-8}$. Excess thermodynamic properties of $n$-butoxyethanols with halogenated compounds of methane have also been determined in our laboratory ${ }^{1,9,10}$. We are not aware of any study on the excess properties of binary mixtures of polyethers with chloroalkanes except with bis(2-methoxyl)ether (diglyme) with chloroalkanes ${ }^{5}$.

Excess molar volumes and viscosities at different mole fraction have been measured for binary mixtures of polar molecules of different sizes and shapes. The $V_{m}{ }^{E}$ values have been analysed using the Prigogine-Flory-Patterson (PFP) model, which takes into account the hydrogen-bonded association.

*For correspondence 
Viscosities of the mixtures, which are of general interest, have been analysed by means of the Bloomfield and Dewan method ${ }^{29}$, based both on the free-volume and the absolute reaction rate theories.

\section{Experimental}

\subsection{Materials}

Materials were of the same origin and purity as used in earlier studies ${ }^{9}$. The sample 1,2dimethoxyethane (Acros, USA, 99,\%) was dried and fractionally distilled as described elsewhere $^{10}$. All liquids were stored in dark bottles and carefully dried over $4 \AA$ molecular sieves to reduce water contents. Before the actual measurements, all liquids were partially degassed under vacuum. Values of their densities recorded at 298.15 K and at atmospheric pressure (table 1) are in good agreement with those in the literature ${ }^{5,11-13}$.

\subsection{Apparatus and procedure}

Excess molar volumes, reproducible to $\pm 0.003 \times 10^{6} \mathrm{~m}^{3} \mathrm{~mol}^{-1}$, were measured directly with a continuous dilution dilatometer as per Dickinson et al. ${ }^{14}$. Details of calibration, experimental setup and measuring procedure have been described elsewhere ${ }^{15}$. The mole fraction of each mixture was obtained to an accuracy of $1 \times 10^{-4}$ from the measured apparent masses of the components. All apparent masses were corrected for buoyancy. Conversion to molar quantities was based on the relative atomic mass table of 1986 issued by IUPAC ${ }^{16}$. Each run covered just over half of the mole fraction range, giving an overlap between two runs.

The kinematic viscosities of pure liquids and liquid mixtures were measured at $298.15 \mathrm{~K}$ and at atmospheric pressure using an Ubbelohde suspended-level viscometer ${ }^{17}$. The viscometer was calibrated with thrice-distilled water and twice-distilled benzene. Care was taken to prevent evaporation during measurements. An average of four or five sets of flow times for each liquid were taken for the purpose of calculation of viscosity. Measured values of the kinematic viscosities were converted to dynamic viscosities $(\eta)$ after multiplication by the density. The estimated error was $\pm 0.003 \mathrm{mPa}$.s. The flow-time measurements were made using an electronic stopwatch with a precision of $\pm 0.01 \mathrm{~s}$. Densities of pure liquids were measured using a double-armed pycnometer with an

Table 1. Densities and viscosities of pure components at $298.15 \mathrm{~K}$.

\begin{tabular}{|c|c|c|c|c|}
\hline \multirow[b]{2}{*}{ Substance } & \multicolumn{2}{|c|}{$\rho\left(\mathrm{g}^{\mathrm{cm}}{ }^{-3}\right)$} & \multicolumn{2}{|c|}{$\eta$ (mPa.s) } \\
\hline & Exp. & Lit. & Exp. & Lit. \\
\hline $\begin{array}{l}\text { 1,2-Dimethoxy } \\
\text { ethane }\end{array}$ & 0.8626 & $\begin{array}{l}0.86262^{11} \\
0.8637^{12} \\
0.86132^{13}\end{array}$ & 0.420 & $0.424^{13}$ \\
\hline Dichloromethane & 1.3165 & $\begin{array}{l}1.3162^{5} \\
1.31678^{12}\end{array}$ & 0.406 & $\begin{array}{l}0.410^{5} \\
0.4043^{12}\end{array}$ \\
\hline Trichloromethane & 1.4794 & $\begin{array}{l}1.4791^{5} \\
1.47970^{12}\end{array}$ & 0.532 & $\begin{array}{l}0.537^{5} \\
0.5357^{12}\end{array}$ \\
\hline Tetrachloromethane & 1.5843 & $\begin{array}{l}1.5843^{5} \\
1.58436^{12}\end{array}$ & 0.905 & $\begin{array}{l}0.900^{5} \\
0.9004^{12}\end{array}$ \\
\hline
\end{tabular}


accuracy of 5 parts in $10^{5}$. The pycnometer was calibrated at $298.15 \mathrm{~K}$ with thricedistilled water. A thermostatically controlled, well-stirred water-bath whose temperature was controlled to $\pm 0.01 \mathrm{~K}$ was used for all the measurements.

\section{Results and discussion}

Experimental results of the excess molar volumes for 1,2-dimethoxyethane + dichloromethane, trichloromethane and tetrachloromethane for a number of mole fractions at atmospheric pressure and $298.15 \mathrm{~K}$ are reported in table 2 . A graphical representation of the experimental results together with the smoothing curves are shown in figure 1.

From the measured values of excess molar volumes, the densities of the liquid mixtures were calculated using the following equation:

$$
\rho=\left(x_{1} M_{1}+x_{2} M_{2}\right) /\left(V_{m}^{E}+x_{1} V_{1}+x_{2} V_{2}\right)
$$

where $x_{1}$ and $x_{2}$ are the mole fractions, $M_{1}$ and $M_{2}$ the molar masses, and $V_{1}$ and $V_{2}$ the molar volumes of 1,2-dimethoxyethane and chloroalkanes respectively. The accuracy in

Table 2. Excess molar volumes for 1,2-dimethoxyethane + chloroalkane systems at $298 \cdot 15 \mathrm{~K}$.

\begin{tabular}{cccccc}
\hline & $V_{m}^{E} \times 10^{6}$ & & $V_{m}^{E} \times 10^{6}$ & & $V_{m}^{E} \times 10^{6}$ \\
$x_{1}$ & $\left(\mathrm{~m}^{3} \cdot \mathrm{mol}^{-1}\right)$ & $x_{1}$ & $\left(\mathrm{~m}^{3} \cdot \mathrm{mol}^{-1}\right)$ & $x_{1}$ & $\left(\mathrm{~m}^{3} \cdot \mathrm{mol}^{-1}\right)$
\end{tabular}

1,2-Dimethoxyethane + dichloromethane

$\begin{array}{llllll}0.0254 & -0.012 & 0.2655 & -0.081 & 0.5919 & -0.108 \\ 0.4568 & -0.019 & 0.3131 & -0.091 & 0.6625 & -0.100 \\ 0.0725 & -0.028 & 0.3408 & -0.100 & 0.7445 & -0.085 \\ 0.1040 & -0.039 & 0.3702 & -0.102 & 0.8352 & -0.063 \\ 0.1412 & -0.056 & 0.3760 & -0.105 & 0.9111 & -0.034 \\ 0.1713 & -0.060 & 0.4078 & -0.106 & 0.9633 & -0.017 \\ 0.2067 & -0.066 & 0.4156 & -0.107 & & \\ \mathbf{0 . 2 5 8 4} & -0.080 & 0.5211 & -0.107 & & \end{array}$

1,2-Dimethoxyethane + trichloromethane

$\begin{array}{llllll}0.0266 & -0.074 & 0.3214 & -0.544 & 0.6944 & -0.351 \\ 0.0549 & -0.155 & 0.3450 & -0.560 & 0.7398 & -0.299 \\ 0.0751 & -0.196 & 0.4120 & -0.567 & 0.7819 & -0.254 \\ 0.1217 & -0.299 & 0.4864 & -0.541 & 0.8752 & -0.140 \\ 0.1633 & -0.377 & 0.5372 & -0.509 & 0.9315 & -0.068 \\ 0.2353 & -0.474 & 0.5967 & -0.457 & 0.9693 & -0.030 \\ 0.3040 & -0.539 & 0.6505 & -0.405 & & \end{array}$

\section{1,2-Dimethoxyethane + tetrachloromethane}

\begin{tabular}{llllll}
0.0133 & -0.004 & 0.3771 & -0.062 & 0.6695 & -0.051 \\
0.0537 & -0.012 & 0.4414 & -0.065 & 0.7130 & -0.054 \\
0.1072 & -0.023 & 0.4749 & -0.069 & 0.7680 & -0.049 \\
0.2031 & -0.039 & 0.5053 & -0.069 & 0.8171 & -0.041 \\
0.2408 & -0.046 & 0.5333 & -0.070 & 0.8626 & -0.036 \\
0.2894 & -0.051 & 0.5679 & -0.068 & 0.9110 & -0.025 \\
0.3153 & -0.056 & 0.6176 & -0.063 & 0.9556 & -0.012 \\
\hline
\end{tabular}




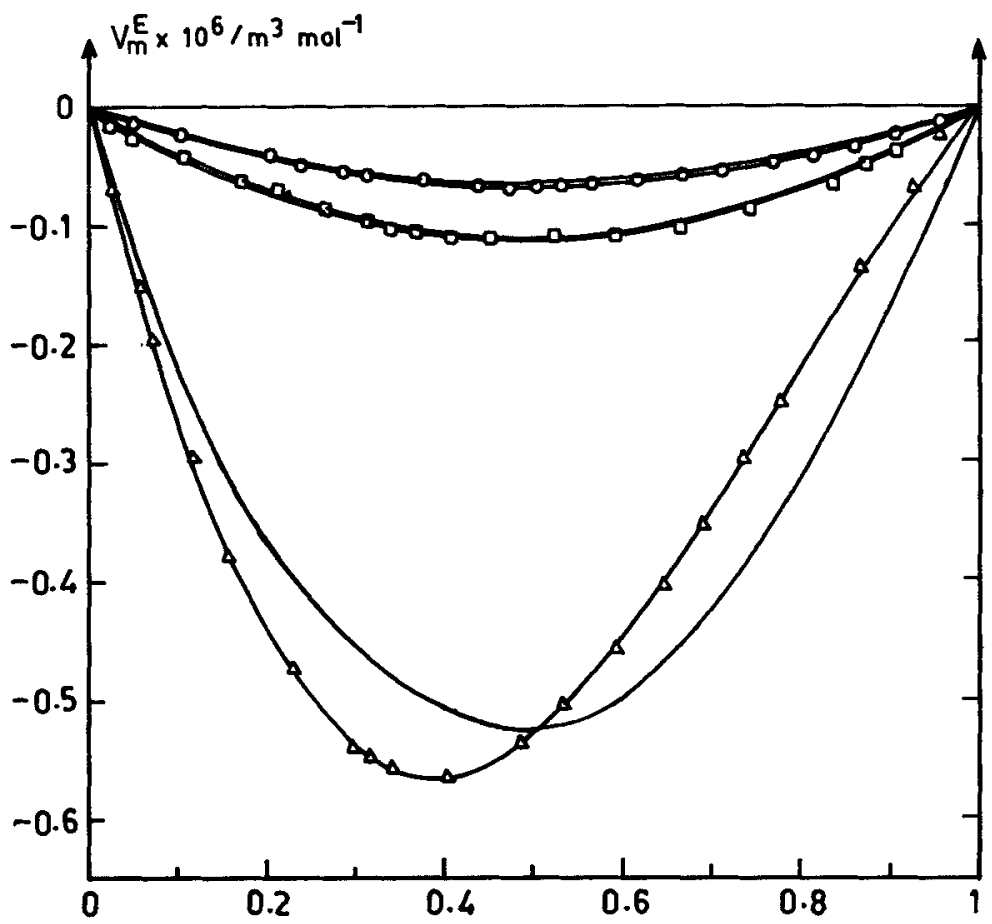

Figure 1. Experimental excess molar volumes for 1,2-dimethoxyethane + dichloromethane, $\square ;+$ trichloromethane, $\Delta ;+$ tetrachloromethane, $O$. Continuous curves were calculated from (4) for experimental data and from PFP theory.

$\rho$ due to the estimated accuracy in excess molar volume $\left( \pm 0.003 \times 10^{6} \mathrm{~m}^{3} \mathrm{~mol}^{-1}\right)$ is $1 \times 10^{-1} \mathrm{~kg} \mathrm{~m}^{-3}$.

The viscosity deviations were obtained from the following relationship ${ }^{18,19}$

$$
\Delta \ln \eta=\ln \eta-\sum_{i=1}^{z} x_{i} \ln \eta_{i}
$$

where $\eta$ is the dynamic viscosity of the mixtures in $\mathrm{mPa}$.s and $\eta_{i}$ is the viscosity of the pure components respectively. The excess energies of activation for viscous flow were obtained using the expression

$$
\Delta G^{* E}=R T\left\{(\ln \eta V)-\sum_{i=1}^{z}\left(x_{i} \ln \eta_{i} V_{i}\right)\right\}
$$

where $V=\sum x_{i} M_{i} / \rho . R$ and $T$ have their usual meanings. Data on derived densities, viscosities and energies of activation for viscous flow for the three systems at $298.15 \mathrm{~K}$ are given in table 3 . 
Table 3. Densities, viscosities and excess energies of activation for viscous flow for the (1,2-dimethoxyethane + chloroalkanes) systems at $298.15 \mathrm{~K}$.

\begin{tabular}{|c|c|c|c|c|c|c|c|}
\hline$x_{1}$ & $\begin{array}{c}\rho \\
\left(\mathrm{g} \cdot \mathrm{cm}^{-3}\right)\end{array}$ & $\begin{array}{c}\eta \\
(\mathrm{mPa} . \mathrm{s})\end{array}$ & $\begin{array}{c}\Delta G^{* E} \\
\left(\mathrm{~J} . \mathrm{mol}^{-1}\right)\end{array}$ & $x_{1}$ & $\begin{array}{l}\rho \times 10^{-3} \\
\left(\mathrm{~g} \cdot \mathrm{cm}^{-3}\right)\end{array}$ & $\begin{array}{c}\eta \\
\text { (mPa.s) }\end{array}$ & $\underset{\left(\mathrm{J} \cdot \mathrm{mol}^{-1}\right)}{\Delta G^{* E}}$ \\
\hline \multicolumn{8}{|c|}{ 1,2-Dimethoxyethane + dichloromethane } \\
\hline 0.0171 & 1.3042 & 0.423 & 104 & 0.4653 & 1.0524 & 0.466 & 373 \\
\hline 0.0277 & 1.2967 & 0.425 & 116 & 0.5302 & 1.0244 & 0.464 & 354 \\
\hline 0.0771 & 1.2630 & 0.434 & 179 & 0.5734 & 1.0067 & 0.462 & 337 \\
\hline 0.1001 & 1.2479 & 0.438 & 210 & 0.6097 & 0.9924 & 0.461 & 324 \\
\hline 0.1399 & 1.2227 & 0.445 & 253 & 0.6569 & 0.9744 & 0.456 & 290 \\
\hline 0.2028 & $1 \cdot 1852$ & 0.454 & 310 & 0.6960 & 0.9600 & 0.453 & 267 \\
\hline 0.2436 & $1 \cdot 1621$ & 0.457 & 329 & 0.7458 & 0.9424 & 0.448 & 228 \\
\hline 0.2505 & 1.1583 & 0.461 & 347 & 0.8150 & 0.9190 & 0.439 & 162 \\
\hline 0.3076 & $1 \cdot 1279$ & 0.464 & 367 & 0.8833 & 0.8973 & 0.431 & 96 \\
\hline 0.3529 & $1 \cdot 1050$ & 0.466 & 379 & 0.9523 & 0.8764 & 0.423 & 30 \\
\hline 0.4105 & 1.0773 & 0.468 & 385 & & & & \\
\hline \multicolumn{8}{|c|}{ 1,2-Dimethoxyethane + trichloromethane } \\
\hline 0.0221 & 1.4630 & 0.557 & 128 & 0.4359 & $1 \cdot 1668$ & 0.646 & 754 \\
\hline 0.0489 & 1.4433 & 0.570 & 202 & 0.5060 & $1 \cdot 1342$ & 0.629 & 718 \\
\hline 0.0775 & 1.4224 & 0.586 & 285 & 0.5591 & 1.1018 & 0.607 & 660 \\
\hline 0.1176 & 1.3935 & 0.605 & 389 & 0.5993 & 1.0778 & 0.590 & 614 \\
\hline 0.1721 & 1.3548 & 0.626 & 504 & 0.6486 & 1.0490 & 0.568 & 550 \\
\hline 0.2143 & 1.3254 & 0.641 & 591 & 0.7139 & 1.0118 & 0.535 & 440 \\
\hline 0.2690 & 1.2879 & 0.657 & 682 & 0.7540 & 0.9896 & 0.516 & 376 \\
\hline 0.3051 & 1.2636 & 0.659 & 714 & 0.8174 & 0.9553 & 0.488 & 270 \\
\hline 0.3442 & 1.2376 & 0.666 & 764 & 0.8600 & 0.9329 & 0.469 & 198 \\
\hline 0.4078 & $1 \cdot 1961$ & 0.658 & 772 & 0.9322 & 0.8960 & 0.441 & 86 \\
\hline \multicolumn{8}{|c|}{ 1,2-Dimethoxyethane + tetrachloromethane } \\
\hline 0.0177 & 1.5706 & 0.897 & 11 & $0-4983$ & 1.2122 & 0.629 & 44 \\
\hline 0.0514 & 1.5447 & 0.876 & 16 & 0.5447 & 1.1789 & 0.606 & 42 \\
\hline 0.0797 & 1.5230 & 0.857 & 18 & 0.5969 & $1 \cdot 1416$ & 0.581 & 39 \\
\hline 0.1051 & 1.5037 & 0.843 & 24 & 0.6426 & $1 \cdot 1092$ & 0.562 & 41 \\
\hline 0.1496 & 1.4699 & 0.818 & 35 & 0.6955 & 1.0719 & 0.537 & 41 \\
\hline 0.2080 & 1.4259 & 0.784 & 40 & 0.7380 & 1.0422 & 0.520 & 30 \\
\hline 0.2738 & 1.3767 & 0.747 & 45 & 0.8135 & 0.9898 & 0.489 & 21 \\
\hline 0.3409 & 1.3270 & 0.711 & 50 & 0.8911 & 0.9365 & 0.458 & 8 \\
\hline 0.3806 & 1.2979 & 0.689 & 47 & 0.9584 & 0.8907 & 0.435 & 6 \\
\hline 0.4421 & 1.2530 & 0.656 & 44 & & & & \\
\hline
\end{tabular}

The results of $V_{m}^{E}, \Delta \ln \eta$, and $\Delta G^{*^{E}}$ are fitted to the Redlich-Kister type equation:

$$
A=x_{1} x_{2} \sum_{i=1}^{n} a_{1}\left(x_{1}-x_{2}\right)^{i-1},
$$

where $a_{i}$ is the polynomial coefficient and $n$ is the polynomial degree. The values of the coefficients, $a_{i}$, obtained by the least-squares method, with all points being given equal 
Table 4. Coefficients $a_{i}$ from (4) and standard deviation, $\sigma$, determined by the method of least squares.

\begin{tabular}{lcrrrrrr}
\hline & & $a_{i}$ & \multicolumn{1}{c}{$a_{2}$} & \multicolumn{1}{c}{$a_{3}$} & $a_{4}$ & $a_{5}$ & \multicolumn{1}{c}{$\sigma$} \\
\hline 1,2-Dimethoxyethane + & & & & & & & \\
dichloromethane & $V_{m}{ }^{E}$ & -0.439 & -0.020 & 0.006 & & & 0.002 \\
& $\Delta \ln \eta$ & 0.490 & -0.166 & -0.106 & -0.317 & 0.372 & 0.007 \\
& $\Delta G^{*}$ & 1484 & -449 & -259 & -804 & 931 & 18 \\
Trichloromethane & $V_{m}{ }^{E}$ & -2.134 & 1.144 & 0.191 & -0.194 & & 0.003 \\
& $\Delta \ln \eta$ & 1.154 & -0.607 & -0.156 & & & 0.006 \\
& $\Delta G^{* E}$ & 2918 & -1494 & -970 & 70 & 1061 & 14 \\
Tetrachloromethane & $V_{m}{ }^{E}$ & -0.270 & -0.012 & 0.022 & -0.043 & & 0.002 \\
& $\Delta \ln \eta$ & 0.073 & -0.037 & 0.010 & & & 0.001 \\
& $\Delta G^{* E}$ & 180 & -89 & 34 & & & 3 \\
\hline
\end{tabular}

weightage, are presented in table 4 along with standard deviations, $\sigma$. In each case, the optimum number of coefficients was ascertained from an examination of the variation of the standard deviation with $n$ :

$$
\sigma=\left[\sum\left(A_{\mathrm{cal}}-A_{\mathrm{obs}}\right)^{2} /\left(n_{\mathrm{obs}}-n\right)\right]^{1 / 2}
$$

where $n_{\mathrm{obs}}$ is the total number of direct experimental values. $A$ represents $V_{m}{ }^{E}, \Delta \ln \eta$ or $\Delta G^{* E}$. For all the mixtures $\sigma\left(V_{m}^{E}\right)<0.003$ for the precision attainable with the dilatometer used.

Excess volume versus composition plots in figure 1 show that the $V_{m}{ }^{E}$ values for all of the mixtures are negative over the whole mole fraction range. The negative values of $V_{m}{ }^{E}$ can be explained by considering the chemical or specific interactions which may have resulted from differences in molecular and free volumes ${ }^{20}$ and possible dipole-dipole interactions leading to weak complex formation. Remarkably, $V_{m}{ }^{E}$ is most negative in the DME[1] + TCM[2] system. The reduction in the magnitude of $V_{m}{ }^{E}$ when dichloromethane is replaced by trichloromethane in the mixture is evidence for the occurrence of specific interaction between 1,2-dimethoxyethane and trichloromethane.

The algebraic values of $V_{m}{ }^{E}$ for all the three binary systems with 1,2-dimethoxyethane (monoglyme) are in the order TCM > DCM > TC. The behaviour is consistent with that of the $V_{m}^{E}$ for bis(2-methoxyl)ether (diglyme) with chloroalkanes ${ }^{5}$. This suggests that when the $n$-alkyl chain end of the polyether is fixed, $V_{m}{ }^{E}$ for both DCM and TC increases in magnitude in the positive direction; with each addition of a $-\mathrm{OC}_{2} \mathrm{H}_{4}$ group in the monoglyme. However the $V_{m}^{E}$ here is more negative for mixtures with TCM. The more significant decrease in $V_{m}{ }^{E}$ for the DME + TCM system indicates possible dipole-dipole interactions between the unlike molecules.

The Prigogine-Flory-Patterson (PFP) theory ${ }^{20-25}$ in the following form has been used to compute $V_{m}^{E}$ of the mixtures:

$$
\frac{V_{m}^{E}}{\left(x_{1} V_{1}^{*}+x_{2} V_{2}^{*}\right)}=\frac{\left(\tilde{v}^{1 / 3}-1\right) \tilde{v}^{2 / 3}}{\left[(4 / 3) \tilde{v}^{1 / 3}-1\right]} \psi_{1} \theta_{2}\left(\frac{\chi_{12}}{\tilde{v}}\right)
$$




$$
-\frac{\left(\tilde{v}_{1}-\tilde{v}_{2}\right)^{2}\left[(14 / 9) \tilde{v}^{-1 / 3}-1\right]}{\left[(4 / 3) \tilde{v}^{-1 / 3}-1\right]} \psi_{1} \psi_{2}+\frac{\left(\tilde{v}_{1}-\tilde{v}_{2}\right)^{2}\left(P_{1}^{*}-P_{2}^{*}\right)}{P_{1}^{*} \psi_{2}+P_{2}^{*} \psi_{1}} \psi_{1} \psi_{2}
$$

where $\psi$ represents the contact energy fraction, given by

$$
\psi_{1}=1-\psi_{2}=\frac{\varphi_{1} P_{1}^{*}}{\varphi_{1} P_{1}^{*}+\varphi_{2} P_{2}^{*}} .
$$

The values of the parameters for the pure liquid components required in the PrigogineFlory-Patterson formalism derived using Flory's expression ${ }^{22,23}$ are presented in table 5. The $\chi_{12}$ parameter was adjusted by fitting the experimental $V_{m}{ }^{E}$ data over the whole concentration range. In table 5 , the $\chi_{12}$ parameters obtained from the PFP theory was used to calculate $V_{m}{ }^{E}$, and figure 1 gives the results together with the experimental values.

We have suggested before that the strong negative values of $V_{m}{ }^{E}$ of 1,2-dimethoxyethane (DME) + trichloromethane (TCM) system is the result of possible chemical interaction; the present results (again highly negative) for $\chi_{12}$ parameters (table 5) reinforce this suggestion.

In this work, dynamic viscosity has also been studied for these systems and often yields valuable information relating to the interaction between the molecules.

The positive values of $\Delta \ln \eta$ show that (i) the mixtures are more viscous than the corresponding ideal mixtures, and (ii) the specific interactions are present, as corroborated by the negative $V_{m}{ }^{E}$ and positive $\Delta G^{* E}$ values shown in figures 2 and 3 . Positive values of the $\Delta G^{* E}$ parameter may be considered ${ }^{26,27}$ to be a useful indicator of the existence of specific interactions ${ }^{28}$ between molecules. There are different expressions available in the literature to calculate $\eta$. Here we have applied the method of Bloomfield and Dewan ${ }^{29}$.

Bloomfield and Dewan ${ }^{29}$ developed an expression from the combination of the theories of free volume and absolute reaction rate,

$$
\Delta \ln \eta=f(\tilde{v})-\Delta G^{R} / R T,
$$

where $f(\tilde{v})$ is the characteristic function of the free volumes defined by

$$
f(\tilde{v})=1 /(\tilde{v}-1)-x_{1} /\left(\tilde{v}_{1}-1\right)-x_{2} /\left(\tilde{v}_{2}-1\right),
$$

\begin{tabular}{|c|c|c|c|c|c|c|c|c|}
\hline & $\alpha \times 10^{-4}$ & $\begin{array}{l}\kappa \times 10^{7} \\
\left(\mathrm{kPa}^{-1}\right)\end{array}$ & $\begin{array}{c}V^{*} \times 10^{6} \\
\left(\mathrm{~m}^{3} \cdot \mathrm{mol}^{-1}\right)\end{array}$ & $\begin{array}{l}P^{*} \times 10^{6} \\
\left({\mathrm{~J} . \mathrm{m}^{-3}}^{-3}\right.\end{array}$ & $T^{*}$ & $\tilde{\boldsymbol{v}}$ & $\widetilde{T}$ & $\chi_{\left(\mathrm{J}_{12} \times 10^{-3}\right)}$ \\
\hline 1,2-Dimethoxyethane & $12 \cdot 77^{32}$ & $11 \cdot 15^{\mathrm{a}}$ & $80 \cdot 25$ & 579 & 4611 & 1.3019 & 0.0647 & \\
\hline Dichloromethane & $13.91^{12}$ & $10 \cdot 26^{12}$ & 48.77 & 707 & 4430 & 1.3227 & 0.0673 & -11.7 \\
\hline Trichloromethane & $12 \cdot 60^{12}$ & $9.98^{12}$ & $62 \cdot 13$ & 635 & 4644 & 1.2987 & 0.0642 & $-36 \cdot 4$ \\
\hline Tetrachloromethane & $12 \cdot 29^{12}$ & $10.80^{12}$ & $10 \cdot 80$ & 567 & 4695 & 1.2928 & 0.0635 & $-4 \cdot 2$ \\
\hline
\end{tabular}

Table 5. Parameters of pure components and Prigogine-Flory-Patterson theory $\left(\chi_{12}\right)$ at $298 \cdot 15 \mathrm{~K}$.

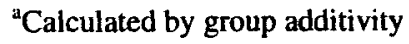




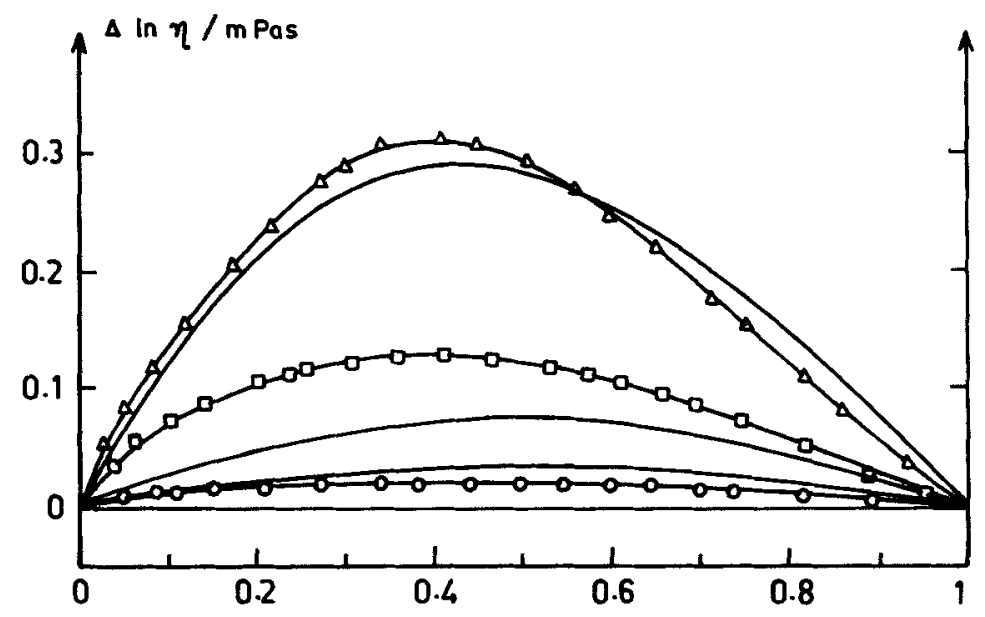

Figure 2. Experimental viscosity deviations for 1,2-dimethoxyethane + dichloromethane, $\square ;+$ trichloromethane, $\Delta ;+$ tetrachloromethane, $O$. Continuous curves were calculated from (4) for experimental data and from Bloomfield and Dewan data ${ }^{29}$.

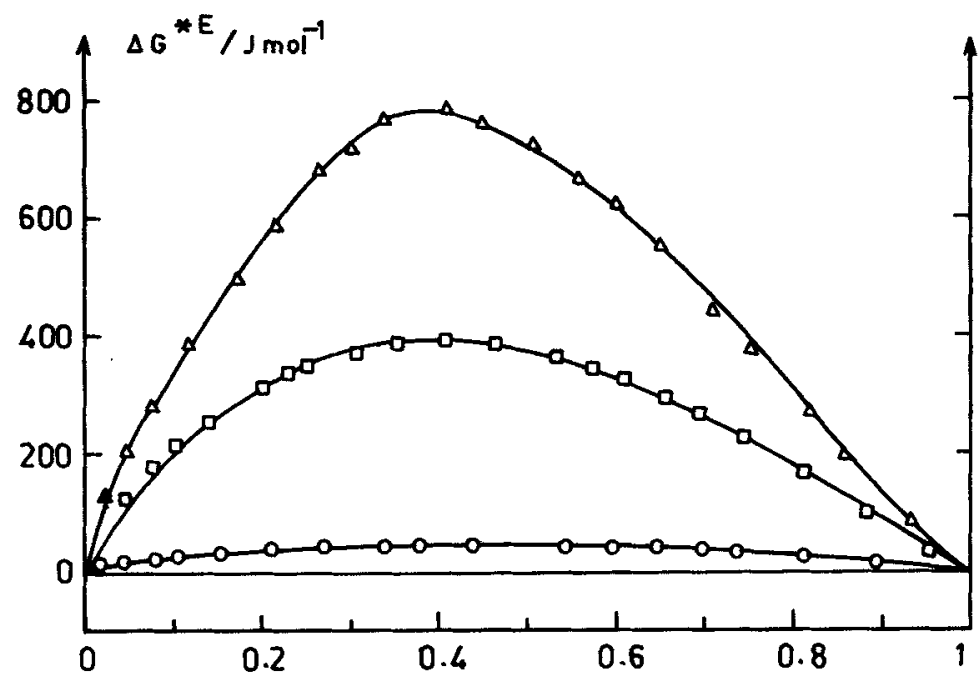

Figure 3. Excess energies of activation for viscous flow for 1,2-dimethoxyethane + dichloromethane, $\square$; + trichloromethane, $\Delta ;+$ tetrachloromethane, $O$. Continuous curves were calculated from (4) for experimental data.

and $\Delta G^{R}$ is the residual energy of mixing, calculated using the expression ${ }^{30}$

$$
\Delta G^{R}=\Delta G^{E}+R T\left(x_{1} \ln x_{1} / \phi_{1}+x_{2} \ln x_{2} / \phi_{2}\right)
$$

The excess free energy can be obtained from the statistical theory of liquid mixtures proposed by Flory and co-workers and is given by 


$$
\begin{aligned}
& \Delta G^{E}=x_{1} P_{1}^{*} V_{1}^{*}\left[1 /\left(\tilde{v}_{1}\right)-1 /(\tilde{v})+3 T_{1} \ln \left\{\left(\tilde{v}_{1}^{1 / 3}-1\right) /\left(\tilde{v}^{1 / 3}-1\right)\right\}\right] \\
& +x_{2} P_{2}^{*} V_{2}^{*}\left[1 /\left(\tilde{v}_{2}\right)-1 /(\tilde{v})+3 T_{2} \ln \left\{\left(\tilde{v}_{2}^{1 / 3}-1\right) /\left(\tilde{v}^{1 / 3}-1\right)\right\}\right]+\left(x_{1} \theta_{2} V_{1}^{*} \chi_{12}\right) / \tilde{v}
\end{aligned}
$$

where the various symbols used have their usual meanings. A similar treatment was given by Katz et $a l^{5}$ and Kanti $e$ t $a l^{31}$.

Using the $\chi_{12}$ values from the fitting values of $V_{m}{ }^{E}$ and table 5 , we have calculated $\Delta G^{R}$ and $f(\tilde{v})$ and finally $\Delta \ln \eta$, according to the Bloomfield and Dewan relationship, which is compared with the experimental data (figure 2). Figure 2 shows that the largest deviation between the estimated and experimental curve occurs for 1,2-dimethoxyethane (DME) + dichloromethane (DCM).

It is interesting to note that in going from tetrachloromethane to trichloromethane, the absolute values of $V_{m}{ }^{E}$ become about five times larger. Since interaction between chloroalkanes and the ether DME cannot imply hydrogen bonding, the relatively larger value of the dipole moment of trichloromethane $(\mu=1.15$ compared with $\mu=1.14$ and 0 of dichloromethane and tetrachloromethane) may be responsible for a decrease in the negative contribution in $V_{m}{ }^{E}$ as is observed here.

Further, an analysis of each of the three contributions to the $V_{m}{ }^{E}, \Delta \ln \eta$, and $\Delta G^{* E}$ of the present mixtures suggests the presence of dipole-dipole interactions in the DME + TCM mixture.

\section{Acknowledgement}

Financial support for this project from the Department of Science and Technology, New Delhi is gratefully acknowledged.

\section{References}

1. Pal A and Kumar A 1998 Fluid Phase Equilibria 143241

2. Pal A and Sharma S 1998 J. Chem. Eng. Data 4321

3. Pal A and Singh W $1996 \mathrm{~J}$. Chem. Thermodyn. 28227

4. Pal A and Dass G 1999 Indian J. Chem. Soc. A38 237

5. de Ruiz Holgado M E, de Schaefer C R, Arancibia E L and Katz M 1994 Fluid Phase Equilibria 95299

6. Inglese A 1992 Thermochim. Acta 199173

7. Spaneda A, Lepori L and Matteoli E 1991 Fluid Phase Equilibria 69209

8. Sharma S C, Joshi J M and Singh Y 1989 J. Chem. Thermodyn. 21331

9. Pal A and Singh W 1997 Fluid Phase Equilibria 129211

10. Pal A and Singh Y P 1996 J. Chem. Eng. Data 411008

11. Douheret G, Davis M I, Hernandez M E and Flores H 1993 J. Indian Chem. Soc. 70395

12. Riddick J A, Bunger W B and Sakano T K 1986 Techniques of chemistry 4th edn. (New York: Wiley-Interscience) vol. 2

13. Das B, Roy M N and Hazra D K 1994 Indian J. Chem. Technol. 193

14. Dickinson E, Hunt D C and McLure I A $1975 \mathrm{~J}$. Chem. Thermodyn. 7731

15. Pal A and Singh Y P 1994 J. Chem. Thermodyn. 261063

16. IUPAC Commission on Atomic Weights and Isotopic Abundances 1985 Pure Appl. Chem. 58 1677

17. Conclaves F A, Kestin J and Sengers J V 1991 Int. J. Thermophys. 121013

18. Aucejo A, Cruz Burguet M, Munoz R and Sanchotello M 1996 J. Chem. Eng. Data 41508

19. Heric E I 1966 J. Chem. Eng. Data 1166

20. Patterson D and Delmas G 1970 Discuss. Faraday Soc. 4998 
21. Prigogine I 1957 The molecular theory of solution (Amsterdam: North Holland)

22. Flory P J 1965 J. Am. Chem. Soc. 871833

23. Abe A and Flory P J 1965 J. Am. Chem. Soc. 871838

24. Costas M and Patterson M 1982 J. Sol. Chem. 11807

25. Riedl B and Delmas G 1983 Can. J. Chem. 611876

26. Reed T M III and Taylor T E 1959 J. Phys. Chem. 6358

27. Meyer R, Meyer M, Metzer J and Peneloux A 1971 J. Chim. Phys. 62405

28. Palepu R, Oliver J and Mackinnon B 1985 Can. J. Chem. 631024

29. Bloomfield V A and Dewan R K 1971 J. Phys. Chem. 753113

30. Celda B, Gavara R and Figueruelo J E 1987 J. Chem. Eng. Data 3231

31. Kanti M, Lagourette B, Alliez J and Boned C 1991 Fluid Phase Equilibria 65291

32. Tovar C A, Carballo E, Claudio A, Cerdeirina and Romani L 1997 J. Chem. Eng. Data 42 1085 